Proceeding Paper

\title{
Estimation of Direct Fire Emissions from Forests Burning in Siberia $^{+}$
}

\author{
Evgenii I. Ponomarev 1,2
}

Citation: Ponomarev, E.I. Estimation of Direct Fire Emissions from Forests Burning in Siberia. Environ. Sci. Proc. 2021, 4, 12. https://doi.org/

10.3390/ecas2020-08114

Academic Editor: Anthony R. Lupo

Published: 13 November 2020

Publisher's Note: MDPI stays neutral with regard to jurisdictional claims in published maps and institutional affiliations.

Copyright: (c) 2020 by the authors. Licensee MDPI, Basel, Switzerland. This article is an open access article distributed under the terms and conditions of the Creative Commons Attribution (CC BY) license (http://creativecommons.org/licenses /by/4.0/).
1 Federal Research Center "Krasnoyarsk Science Center, Siberian Branch, Russian Academy of Sciences", 660036 Krasnoyarsk, Russia; evg@ksc.krasn.ru; Tel.: +7-391-249-4092

2 Siberian Federal University, Department of Ecology and Environment, 660041 Krasnoyarsk, Russia

† Presented at the 3rd International Electronic Conference on Atmospheric Sciences, 16-30 November 2020; Available online: https://ecas2020.sciforum.net/.

\begin{abstract}
Using a database on wildfires recorded by remote sensing for 1996-2020, we assessed the seasonal variation of direct carbon emissions from the burning in Siberian forests. We have implemented an approach that takes into account the combustion parameters and the changing intensity of the fire (in terms of Fire Radiative Power (FRP)), which affects the accuracy of the emission estimate. For the last two decades, the range of direct carbon emissions from wildfires was 20-250 Tg C per year. Sporadic maxima were fixed in 2003 (>150 Tg C/year), in 2012 (>220 Tg C/year), and in 2019 (>190 Tg C/year). Preliminary estimation of emissions for 2020 (on 30th of September) was $\sim 180 \mathrm{Tg}$ C/year. Fires in the larch forests of the flat-mountainous taiga region (Central Siberia) made the greatest contribution $(>50 \%)$ to the budget of direct fire emission, affecting the quality of the atmosphere in vast territories during the summer period. According to the temperature rising and forest burning trend in Siberia, the fire emissions of carbon may double (220 Tg C/year) or even increase by an order of magnitude (>2000 Tg C/year) at the end of the 21st century, which was evaluated depending on IPCC scenario.
\end{abstract}

Keywords: wildfire; larch forests; Siberia; emissions; fire radiative power; remote sensing

\section{Introduction}

Direct emissions from Siberian wildfires are the significant factor affecting the quality of the atmosphere in vast territories during the season of active burning in forests (March-September). Smoke plumes can transport several thousand kilometers from the zone of active wildfires depending on the fire numbers, areas and duration of burning and current meteorological conditions as well [1-3]. In recent decades, wildfires of the boreal zone $\left(60-70^{\circ} \mathrm{N} ; 90-130^{\circ} \mathrm{E}\right)$ of Siberia annually cause an increase in concentration of smoke over Siberia in summertime. Smoke reaches the main cities of the central part and south of Siberia (Novosibirsk, Krasnoyarsk, Yakutsk, and Irkutsk etc.) regularly. In some years the smoke from Siberia was transferred to the European part of Russia (in 2012, 2016), or to the Far Eastern part of Russia (in 2003), as well as to the Arctic (in 2019) [3-5].

Estimates of carbon emissions in Siberia are discussed for a long time [6-8]. However, there are some limitations in the accuracy of emission estimates. It is necessary to take into account the differences in burning intensity, and therefore to calculate differentially the emissions from each part of the burnt area, which could be characterized by a variety of burning characteristics $[1,2,9]$. Using satellite data $[1,10]$ it is possible to obtain accurate estimates on wildfires area, forest burnt plots, and the intensity of combustion for different parts of the wildfire. It was shown [11] that the biomass combustion rate is linearly related to Fire Radiative Power (FRP), which could be evaluated from satellite imagery of 4-mkm band. To use it, a remote sensing approach for wildfire's energy estimate could be 
used $[12,13]$. Thus, a refinement of the combusted biomass and carbon emissions estimates requires to be performed by accounting for variations in the combustion characteristics within each fire polygon.

The extreme estimates for the direct fire emissions from the fires in Siberia are $>500 \mathrm{Tg} \mathrm{C} /$ year [6], which seems to be overestimated when compared to data for Canada (>300 Tg C/year) [14] as well as to averaged data for Siberia (120-140 Tg/year) [8]. Although, taking into account climatic changes, this indicator in Siberia is predicted to be up to $240 \mathrm{Tg} /$ year in the second half of the 21st century [15]. Currently, the problem of quantitative estimates of fire emissions is not completely solved.

The aim of this study was to estimate long-term variety of direct fire emission of carbon based on the satellite data on wildfires and Fire Radiative Power (FRP) measurements.

\section{Experiments}

\subsection{Study Area}

The territory of Siberia $\left(50-70^{\circ} \mathrm{N}\right.$ and $\left.60-150^{\circ} \mathrm{E}\right)$ encompasses about $9.7 \times 10^{6} \mathrm{~km}^{2}$ (Figure 1). The forested area of Siberia is estimated at $6.0 \times 10^{6} \mathrm{~km}^{2}$. The majority of Russian forests $(\sim 70 \%$, including sparse stands) are located in Siberia. The major Siberian forest types are dominated by larch (Larix sibirica, L. gmelinii, and L. cajanderi), Scots pine (Pinus sylvestris), dark needled conifers (Pinus sibirica, Abies sibirica, and Picea obovata), birch (Betula spp.), and aspen (Populus tremula) species. Forests dominated (based on data from Vega-service, Available online: http://pro-vega.ru/maps/ (accessed on 15 November 2020) [16]) by larch range over an area of $2.7-3.0 \times 10^{6} \mathrm{~km}^{2}$; an area of Scots pine stands extends over $1.0 \times 10^{6} \mathrm{~km}^{2}$, dark coniferous stands occupy $0.75 \times 10^{6} \mathrm{~km}^{2}$, and mixed forest covers about $0.77 \times 10^{6} \mathrm{~km}^{2}$.

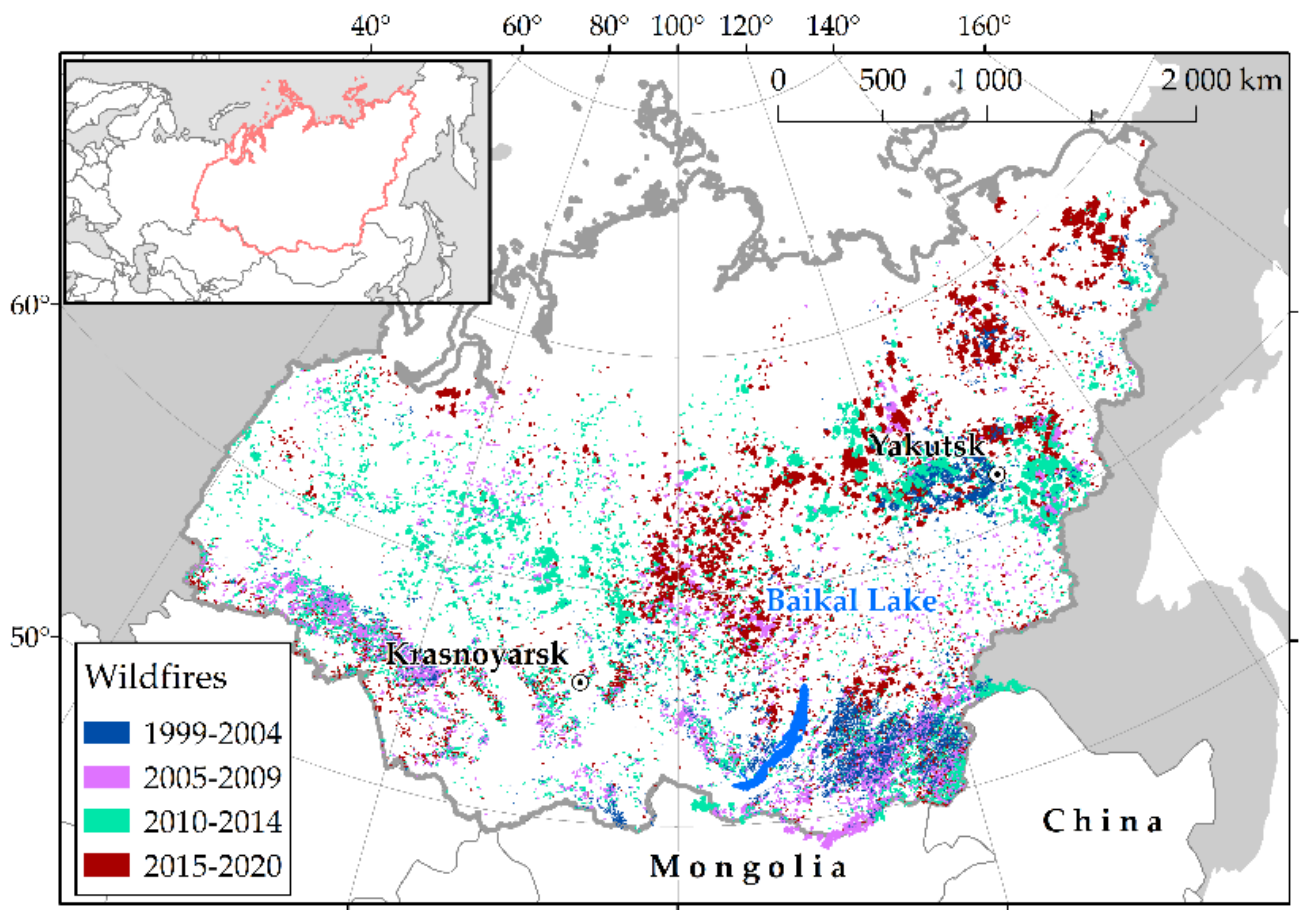

Figure 1. Territory of Siberia and spatial distribution of wildfires (Selection for burned area $>2000$ ha) in 1999-2020. 


\subsection{Data on Wildfires}

We considered all forest fires detected by remote sensing technology over the territory of Siberia (Figure 1). But since we used FRP data from Terra/MODIS, we could evaluate emission estimates for 2002-2020 only. We used our own wildfires attributive data collected using Terra and Aqua/MODIS imagery in the V.N. Sukachev Institute of Forest of Federal Research Center "Krasnoyarsk Science Center, Siberian Branch, Russian Academy of Sciences" (Krasnoyarsk, Russia) [17]. Active fire products of MODIS data for fire detection (MOD14/MYD14) with estimates of fire radiative power (FRP) were acquired from the Level-1 and Atmosphere Archive and Distribution System (LAADS) Distributed Active Archive Center (DAAC) website (Available online: https://ladsweb.modaps. eosdis.nasa.gov/ (accessed on 15 November 2020)).

\subsection{Methods}

We linked each record from the wildfire database to forest type available for Siberia from the Vega-service (Service of the Russian Academy of Sciences' Space Research Institute, IKI, Moscow, Russia) resource [16] using geoinformation system (GIS) procedure of intersection of vector layers. Forest types characteristics and pre-fire fuel loads were summarized from field obtained data $[1,6,7,18,19]$.

Next, we classified the fire pixels into three categories of FRP using thresholds, which were calculated on statistics of fire radiative power distribution (FRP mean and Standard Deviation) under the conditions of burning in forests of Siberia. Three categories of fire pixels were separated: fires pixels of low FRP (FRP $<$ FRPmean $-\sigma)$, fires pixels of medium FRP (FRPmean $-\sigma<$ FRP $<$ FRPmean $+\sigma$ ), and fires pixels of high FRP (FRP $>$ FRPmean + $\sigma)[20]$. We distinguished areas of fires corresponding to low, medium, and high FRP. Thus, the parameter of burned area $\left(\mathrm{A}, \mathrm{m}^{2}\right)$ was represented as the sum of the areas having various FRP values:

$$
\mathrm{A}=\sum_{i} \mathrm{~A}_{i}\left(\mathrm{FRP}_{i}\right)
$$

The combusted biomass and carbon emissions were calculated using the method of [21], taking into account the burned area $\left(\mathrm{A}, \mathrm{m}^{2}\right)$, the combusted biomass $(\mathrm{kg})$, the combustion completeness coefficient $(\beta)$, the pre-fire fuel load $\left(\mathrm{kg} / \mathrm{m}^{2}\right)$, and the emission factor $(\mathrm{g} / \mathrm{kg})$. The pre-fire fuel loads $\left(\mathrm{B}=1.38-5.4 \mathrm{~kg} / \mathrm{m}^{2}\right)$ for the sub-regions of Siberia were obtained from published data $[7,18,19]$. We used generalized data on on-ground fuels in forests with prevalence of larch, pine, dark coniferous, and deciduous stands as the input parameter. The value of $\beta$ for each fire part was determined according to the FRP category $\beta=\beta_{\mathrm{i}}(\mathrm{FRP} \mathrm{i})=0.35-0.60$. The coefficient $\beta$ was selected as $0.35-0.40$ for low FRP, $0.40-0.45$ for medium FRP, and $0.45-0.60$ for high FRP. We considered also various empirical estimates $[1,6,7]$ of forest fuels combusted during wildfires of various intensities: $0.11-0.97 \mathrm{~kg} / \mathrm{m}^{2}, 0.86-2.15 \mathrm{~kg} / \mathrm{m}^{2}$, and $2.25-5.36 \mathrm{~kg} / \mathrm{m}^{2}$, respectively, for low-, medium-, and high-intensity fires.

\section{Results and Discussion}

\subsection{Ratio of Burned Areas in Forests of Siberia}

Most of the MODIS fire pixels (up to $88 \%$ of the total) had FRP values below $50 \mathrm{MW} / \mathrm{km}^{2}$. The mean FRP value at the $95 \%$ confidence level was $37.4 \mathrm{MW} / \mathrm{km}^{2}$ $\left(\sigma=17.1 \mathrm{MW} / \mathrm{km}^{2}\right)$. Two threshold values were defined to separate fire pixels by FRP categories: $20.3 \mathrm{MW} / \mathrm{km}^{2}$ and $54.5 \mathrm{MW} / \mathrm{km}^{2}$ [22]. According to the FRP categories, the proportion of low, medium, and high intensity burning was classified for different forests of Siberia in terms of dominant tree species. We obtained a current ratio of burned areas of low-, moderate-, and high-intensity fires in Siberia as $47.0 \pm 13.6 \%, 42.5 \pm 10.5 \%$, and $10.5 \pm 6.9 \%$ correspondingly $[20,23]$. An instrumental-based estimation of the areas burned 
by fires of various intensities in Siberia was performed for the first time. In previous studies, empirically obtained data indicated that the burned areas corresponded to $22 \%, 38.5 \%$, and $38.5 \%$ for low-, medium-, and high-intensity fires, respectively [6]. Previously, we estimated [23] high-intensity crown fires as being $8.5 \%$ of the total burned forested area in Siberia.

Wildfires are the most important and permanent driver of forest dynamics in Siberia, but their impacts vary significantly in different forest types. Maximal burning rate was observed within larch-dominated and Scots pine stands, while the lowest rates occur in dark needle coniferous stands (Table 1).

Table 1. The percentage of total fire occurrences and burned area by Siberian forest types.

\begin{tabular}{ccc}
\hline Dominated Tree Stand & Fire Number, \% of Total & Burned Area, \% of Total \\
\hline Larch (Larix sibirica, L. dahurica, L. cajanderi) & 41.2 & 65.15 \\
Scots pine (Pinus sylvestris) & 26.17 & 17.95 \\
Deciduous (Populus tremula and Betula spp.) & 22.26 & 10.15 \\
Oark needle coniferous (Pinus sibirica, Abies sibirica, Picea obovata) & 7.97 & 5.68 \\
Other types/Tundra & 2.48 & 1.07 \\
\hline
\end{tabular}

The assessments made using satellite data are similar to published data for burned areas in larch forests (up to $50 \%$ of the total), dark coniferous (about 5\%), light coniferous, and deciduous (18\% and 19\%, respectively) [6,19].

Fires in the larch forests of the flat-mountainous taiga region (Central Siberia) made the greatest contribution (more than 65\%) to the total annual burned area. It is the reason for the highest value of direct emission ( $>51 \%$ annually) obtained from burning in larch forests (see Table 2).

Table 2. Carbon emission estimates per year (Tg C/year) and per ha (Mg C/ha) in Siberia (range for moderate and extreme fire seasons).

\begin{tabular}{cccc}
\hline Tree Stand Type & Tg C/Year & Mg C/ha & \% of Annual Emission (Min-Max) \\
\hline Larch & $43.0-52.0$ & $15.5-18.8$ & $51.6-62.4$ \\
Pine & $11.0-12.0$ & $16.7-18.0$ & $13.2-14.2$ \\
Dark coniferous & $1.9-3.1$ & $12.7-20.4$ & $2.3-3.7$ \\
Deciduous/mixed & $3.8-5.0$ & $13.7-17.5$ & $4.5-5.7$ \\
\hline
\end{tabular}

\subsection{Direct Carbon Emissions}

Our estimate (Figure 2, Table 2) of carbon emissions from wildfires of Siberia was $85 \pm 20 \mathrm{Tg} /$ year. Between 2002 and 2020, direct fire emissions varied from the minimum values of 20-40 Tg/year (low fire danger scenarios of 2004, 2005, 2007, 2009, 2010) to a maximum of $\sim 200 \mathrm{Tg} /$ year in the extreme fire danger seasons (2012 and 2019). We obtained also preliminary estimation of emissions for 2020 (on 30th of September) which is $\sim 180 \mathrm{Tg} /$ year, although there are still some active burning areas in the eastern part of Siberia at the end of September.

Our estimates are significantly lower than the previous extreme assessments for Siberian fires, which were from $116 \mathrm{Tg} \mathrm{C} /$ year in 1999 up to >500 Tg C/year in 2002, obtained by Soja et al. (2004) [6]. However, the long-term dynamics of carbon emissions shows a positive trend corresponding to rising of forest burning in Siberia [24,25]. Thus, under conditions of air temperature rising [26], we should expect a correlation between the fire emissions and climate change. Current relation [4] was used for forecasting the emission level under available climate scenarios [27]. In case of RCP2.6 scenario the average air temperature increased by $0.3-1.7^{\circ} \mathrm{C}$; in case of "harsh" scenario (RCP8.5) the temperature rose by 2.6-4.8 ${ }^{\circ} \mathrm{C}$ [27]. Thus, according to current trends (Figure 1), the fire emissions in Siberia may reach $220-700 \mathrm{Tg} \mathrm{C} /$ year at the end of 21st century. While extreme value of $2300 \mathrm{Tg}$ C/year was evaluated for the conditions of "harsh" scenario $[4,15,24]$. 


\section{C, $\mathrm{Tg} /$ year}

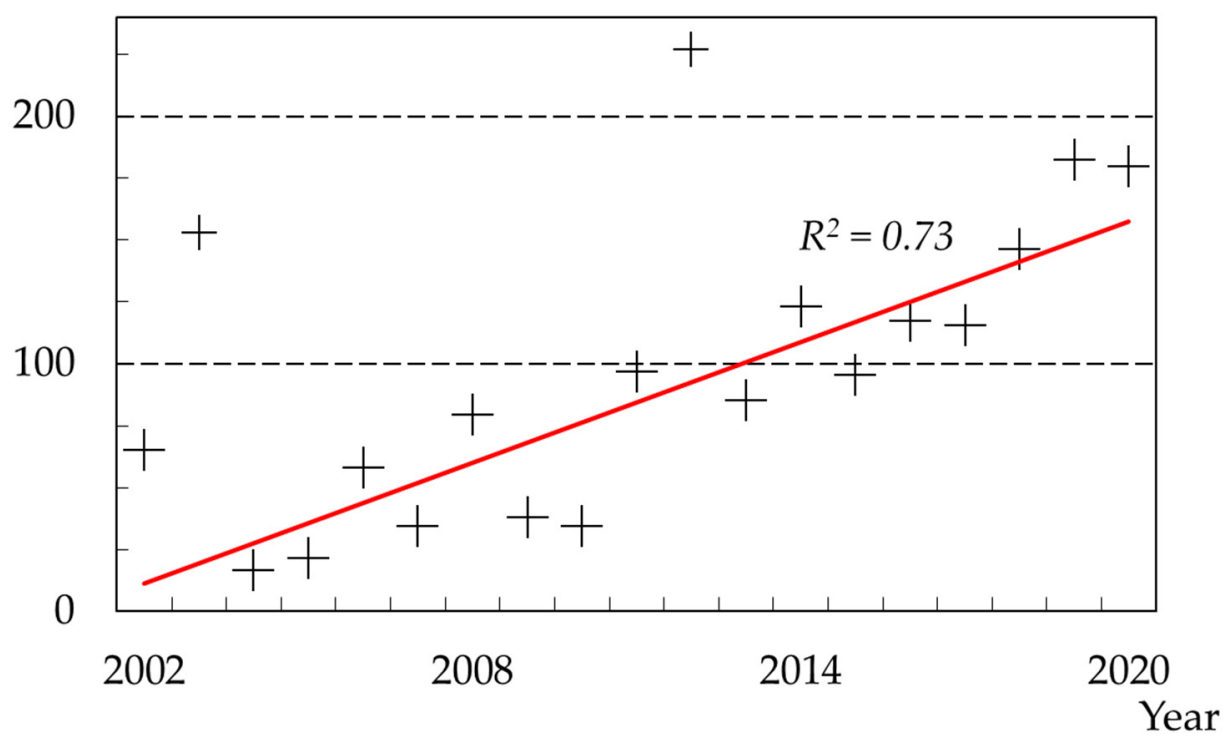

Figure 2. Annual direct carbon emission estimates for 2002-2020 and linear trend of rising $\left(R^{2}=0.73\right)$ for the territory of Siberia.

\section{Conclusions}

A proposed improvement of the method for accounting for burned areas allowed us to evaluate the range of direct fire emissions as $20-250 \mathrm{Tg} C /$ year. However, according to the current temperature trend as well as to the current forest burning trend in Siberia, the carbon emissions from fires may double (220 Tg C/year) or even increase by an order of magnitude ( $>2000 \mathrm{Tg}$ C/year) at the end of the 21st century, which is dependent on the IPCC (The Intergovernmental Panel on Climate Change) scenario. Thus, the impact of fire emissions on air quality in Siberia is likely to become more significant in the nearest future.

Funding: This research was funded by the Russian Foundation for Basic Research, Government of the Krasnoyarsk region, and Krasnoyarsk krai Foundation for Research and Development Support, no. 20-44-242002, grant number 17-41-240475, 20-44-242002.

\section{Institutional Review Board Statement: Not applicable.}

Informed Consent Statement: Not applicable.

Data Availability Statement: Publicly available datasets were analyzed in this study. This data can be found here: https://ladsweb.modaps.eosdis.nasa.gov/ (accessed on 15 November 2020).

Acknowledgments: Equipment was used in the Laboratory of Space Systems and Technologies and the Center of Collective Use, Federal Research Center "Krasnoyarsk Science Center SB RAS" (Krasnoyarsk, Russia).

Conflicts of Interest: The author declares no conflict of interest. 


\section{References}

1. Conard, S.G.; Sukhinin, A.I.; Stocks, B.J.; Cahoon, D.R.; Davidenko, E.P.; Ivanova, G.A. Determining effects of area burned and fire severity on carbon cycling and emissions in Siberia. Clim. Chang. 2002, 55, 197-211.

2. McRae, D.J.; Conard, S.G.; Baker, S.P.; Samsonov, Y.N.; Ivanova, G.A. Fire emissions in central Siberia. In The Canadian Smoke Newsletter Fall; Miscellaneous Publications: Jackson, MS, USA, 2009; pp. 9-13.

3. Bondur, V.G.; Gordo, K.A.; Kladov, V.L. Spacetime Distributions of Wildfire Areas and Emissions of Carbon-Containing Gases and Aerosols in Northern Eurasia according to Satellite-Monitoring Data. Izv. Atmospheric Ocean. Phys. 2017, 53, 859-874, doi:10.1134/s0001433817090055.

4. Ponomarev, E.I.; Shvetsov, E.G.; Kharuk, V.I. The Intensity of Wildfires in Fire Emissions Estimates. Russ. J. Ecol. 2018, 49, 492499, doi:10.1134/s1067413618060097.

5. Panov, A.V.; Prokushkin, A.S.; Bryukhanov, A.V.; Korets, M.A.; Ponomarev, E.; Sidenko, N.V.; Zrazhevskaya, G.K.; Timokhina, A.V.; Andreae, M.O. A Complex Approach for the Estimation of Carbonaceous Emissions from Wildfires in Siberia. Russ. Meteorol. Hydrol. 2018, 43, 295-301, doi:10.3103/s1068373918050035.

6. Soja, A.J.; Cofer, W.R.; Shugart, H.H.; Sukhinin, A.I.; Jr., P.W.S.; McRae, D.J.; Conard, S.G. Estimating fire emissions and disparities in boreal Siberia (1998-2002). J. Geophys. Res. Space Phys. 2004, 109, doi:10.1029/2004jd004570.

7. Ivanova, G.A.; Ivanov, V.A.; Kukavskaya, E.A.; Conard, S.G.; McRae, D.J. Effect of Fires on Carbon Emission in the Pine Forests of Middle Siberia. Sib. J. Ecol. 2007, 14, 885-895. (In Russian)

8. Shvidenko, A.Z.; Shchepashchenko, D.G.; Vaganov, E.A.; Sukhinin, A.I.; Maksyutov, S.S.; McCallum, I.; Lakyda, I.P. Impact of wildfire in Russia between 1998-2010 on ecosystems and the global carbon budget. Dokl. Earth Sci. 2011, 441, 1678-1682, doi:10.1134/s1028334x11120075.

9. Kukavskaya, E.A.; Soja, A.J.; Petkov, A.P.; Ponomarev, E.I.; Ivanova, G.A.; Conard, S.G. Fire emissions estimates in Siberia: evaluation of uncertainties in area burned, land cover, and fuel consumption. Can. J. For. Res. 2013, 43, 493-506, doi:10.1139/cjfr2012-0367.

10. Bartalev, S.A.; Stytsenko, F.V.; Egorov, V.A.; Loupian, E.A. Satellite assessment of fire-caused forest mortality in Russia. Forestry (Lesovedenie) 2015, 2, 83-94. (In Russian)

11. Wooster, M.J.; Roberts, G.; Perry, G.L.W.; Kaufman, Y.J. Retrieval of biomass combustion rates and totals from fire radiative power observations: FRP derivation and calibration relationships between biomass consumption and fire radiative energy release. J. Geophys. Res. Space Phys. 2005, 110, doi:10.1029/2005jd006318.

12. Ichoku, C.; Kaufman, Y. A method to derive smoke emission rates from MODIS fire radiative energy measurements. IEEE Trans. Geosci. Remote Sens. 2005, 43, 2636-2649, doi:10.1109/tgrs.2005.857328.

13. Vermote, E.; Ellicott, E.; Dubovik, O.; Lapyonok, T.; Chin, M.; Giglio, L.; Roberts, G.J. An approach to estimate global biomass burning emissions of organic and black carbon from MODIS fire radiative power. J. Geophys. Res. Space Phys. 2009, 114, 1-22, doi:10.1029/2008jd011188.

14. Amiro, B.; Cantin, A.; Flannigan, M.; De Groot, W. Future emissions from Canadian boreal forest fires. Can. J. For. Res. 2009, 39, 383-395, doi:10.1139/x08-154.

15. Zamolodchikov, D.G.; Grabovskii, V.I.; Kraev, G.N. Dynamics of Carbon Budget in Forests of Russia for Last Twenty Years. Forestry 2011, 6, 16-28. (In Russian).

16. Balashov, I.; Bartalev, S.; Burtsev, M.; Vorushilov, I.; Egorov, V.; Kashnitskii, A.; Khovratovich, T.; Khvostikov, S.; Kobets, D.; Loupian, E.; et al. Vega-Les Information System. Actual Features and Future Evolution. In Proceedings of the IOP Conference Series: Earth and Environmental Science, Putrajaya, Malaysia, 16-17 October 2020; Volume 507, p. 012002.

17. Ponomarev, E.I.; Shvetsov, E.G. Satellite detection of forest fires and geoinformation methods for calibrating of the result. Issledovanie Zemli iz Kosmosa (Remote Sens.) 2015, 1, 84-91, doi:10.7868/S0205961415010054. (In Russian)

18. Tsvetkov, P.A. Adaptation of Larix gmelinii to Fires in the Northern Taiga of Central Siberia. Sib. J. Ecol. 2005, 1, 117-129. (In Russian).

19. De Groot, W.J.; Cantin, A.S.; Flannigan, M.D.; Soja, A.J.; Gowman, L.M.; Newbery, A. A comparison of Canadian and Russian boreal forest fire regimes. For. Ecol. Manag. 2013, 294, 23-34, doi:10.1016/j.foreco.2012.07.033.

20. Ponomarev, E.; Shvetsov, E.G.; Litvintsev, K.Y. Calibration of Estimates on Direct Wildfire Emissions from Remote Sensing Data. Izv. Atmospheric Ocean. Phys. 2019, 55, 1065-1072, doi:10.1134/s0001433819090408.

21. Seiler, W.; Crutzen, P.J. Estimates of gross and net fluxes of carbon between the biosphere and atmosphere from biomass burning. Clim. Chang. 1980, 2, 207-247, doi:10.1007/BF00137988.

22. Shvetsov, E.G.; Ponomarev, E. Postfire Effects in Siberian Larch Stands on Multispectral Satellite Data. Contemp. Probl. Ecol. 2020, 13, 104-112, doi:10.1134/s1995425520010096.

23. Ponomarev, E.I.; Shvetsov, E.G.; Usataya, Y.O. Determination of the Energy Properties of Wildfires in Siberia by Remote Sensing. Izv. Atmospheric Ocean. Phys. 2018, 54, 979-985, doi:10.1134/s000143381809030x.

24. Shvidenko, A.Z.; Schepaschenko, D.G. Climate change and wildfires in Russia. Contemp. Probl. Ecol. 2013, 6, 683-692, doi:10.1134/s199542551307010x.

25. Ponomarev, E.I.; Kharuk, V.I.; Ranson, J.K. Wildfires Dynamics in Siberian Larch Forests. Forests 2016, 7, 1-9, doi:10.3390/f7060125. 
26. Ponomarev, E.I.; Kharuk, V.I. Wildfire occurrence in forests of the Altai-Sayan region under current climate changes. Contemp. Probl. Ecol. 2016, 9, 29-36, doi:10.1134/s199542551601011x.

27. IPCC. 2014: Climate Change 2014: Impacts, Adaptation, and Vulnerability. Summaries, Frequently Asked Questions, and Cross-Chapter Boxes. Report of the Intergovernmental Panel on Climate Change; Field, C.B., Barros, V., Dokken, D.J., Eds.; World Meteorological Organization: Geneva, Switzerland, 2014. 